\title{
Current care services provided for patients with COPD in the Eastern province in Saudi Arabia: a descriptive study
}

This article was published in the following Dove Press journal:

International Journal of COPD

4 November 2015

Number of times this article has been viewed

\author{
Mohammed E Alsubaiei ${ }^{1,2}$ \\ Paul A Cafarella ${ }^{1,2}$ \\ Peter A Frith ${ }^{1,2}$ \\ R Doug McEvoy, ${ }^{2,3}$ \\ Tanja W Effing ${ }^{1,2}$
}

'Repatriation General Hospital, Department of Respiratory Medicine, Adelaide, SA, Australia; ${ }^{2}$ Flinders University, School of Medicine, Adelaide, SA, Australia; ${ }^{3}$ Repatriation General Hospital, Sleep and Respiratory Medicine, Southern Adelaide Local Health Network, Daw Park, SA, Australia
Correspondence: Mohammed E Alsubaiei Repatriation General Hospital, Department of Respiratory Medicine, Daws Road, Daw Park, SA, 504I Australia

Tel +6I 43 58| 9667

Email prof_pt2006@hotmail.com
Background: COPD is a leading cause of morbidity and mortality worldwide. The prevalence rate of COPD in the general Saudi population is estimated to be $2.4 \%$ and $14.2 \%$ among smokers. Not much is known about current health care services for patients with COPD in Saudi Arabia. The objective of this study was to determine the current care services for patients with COPD provided by government hospitals in the Eastern province of Saudi Arabia.

Methods: A cross-sectional study was conducted in the Eastern province of Saudi Arabia. Directors of the Department of Internal Medicine from all 22 general government hospitals that are under the responsibility of the Ministry of Health or the Ministry of Higher Education in this region were asked to participate. Data were collected using a questionnaire.

Results: The study results indicated that there are limited hospital facilities for patients with COPD: no respiratory departments in any of the included hospitals, no spirometry in $77.3 \%$ of the hospitals, no intensive care units in $63.7 \%$ of the hospitals, and no pulmonary rehabilitation program in any of the hospitals. Among the included 22 hospitals, 24 respiratory physicians, 29 respiratory therapists, and three physiotherapists were involved in COPD care.

Conclusion: In conclusion, current care services provided by government hospitals in the Eastern province of Saudi Arabia for patients with COPD do not meet international recommendations for COPD management. Increased awareness, knowledge, and implementation of COPD guidelines by health care providers will most probably improve COPD management in Saudi Arabia. In addition, the government could improve dissemination of information about COPD management through national programs and by offering specific education regarding respiratory diseases.

Keywords: health services, pulmonary disease, chronic obstructive, Saudi Arabia, hospitals, general

\section{Introduction}

COPD affects $>65$ million people worldwide and is characterized by inflammation, airway obstruction, and worsening in lung function that is not fully reversible. ${ }^{1-4}$ The long-term management of patients with COPD adds substantially to health care costs, economic burden, and poor quality of life of patients. ${ }^{5,6}$ Although COPD is a serious respiratory disease with an already high and still increasing morbidity and mortality, it is underdiagnosed and underrecognized in Middle Eastern countries, including Saudi Arabia. ${ }^{7}$

A recent study estimated the prevalence rate of COPD in Saudi Arabia at 2.4\%, similar to the prevalence rate in the entire Middle East (3.6\%). ${ }^{8}$ A Saudi study among smokers older than 40 years of age reported that $14.2 \%$ had COPD. ${ }^{9,10}$ This prevalence rate is comparable to rates in smoking populations in Turkey. ${ }^{9,10}$ According to the Saudi 
Ministry of Health (MOH), chest diseases were the fourth leading cause of death in Saudi Arabia in 2010. ${ }^{11}$

Smoking is the main risk factor for the development and progression of COPD. ${ }^{9}$ Evidence suggests that the smoking rate is steadily increasing among Saudis ${ }^{9}$ and is currently 27.9\%. ${ }^{12}$ COPD prevalence rates in Saudi Arabia are therefore expected to rise even further. ${ }^{9}$ Other risk factors for developing COPD in Saudi Arabia are outdoor air pollution, desert dust, wars (eg, chemical weapons), and childhood respiratory infections. ${ }^{13}$

Saudi Arabia has a population of $\sim 30$ million people who live in 13 provinces, of which the Eastern province is the largest (with $>4$ million inhabitants and 34 government hospitals). ${ }^{14}$ The Eastern, Central, and Makkah provinces have the highest population and the highest number of training centers that provide specialized programs for physicians in Saudi Arabia. ${ }^{11}$ Their health services therefore differ positively from the other ten provinces, for example, more hospitals, beds, health care providers, and funds. ${ }^{11}$

The number of physicians and nurses per 10,000 people in Saudi Arabia is estimated to be 11.6 and 28, respectively, ${ }^{15}$ substantially lower than in some other Middle East countries (eg, Kuwait: 18 and 37 per 10,000 and Bahrain: 30 and 58 per 10,000) and in most developed countries (eg, US: 27 and 98 per 10,000). ${ }^{15}$ This lack of health care providers may compromise health care in Saudi Arabia. ${ }^{15}$

To date, there are several national and international clinical COPD management guidelines such as the recently published Saudi Initiative for Chronic Airway Disease (SICAD) guidelines and the internationally recognized and frequently updated Global Initiative for Chronic Obstructive Lung Disease (GOLD) guidelines. ${ }^{7,16}$ The SICAD guidelines panel has customized and simplified the GOLD guidelines based on the Saudi setting. ${ }^{7,16}$ Whereas COPD guidelines are widely accessible, many physicians and pulmonologists are not aware of their existence or do not fully understand them. ${ }^{17}$ Indeed, adherence to COPD guidelines in clinical practice in most countries is not satisfactory. ${ }^{17-21}$ This has been attributed to lack of awareness and time constraints of physicians and pulmonologists, as well as disagreement with the recommendations. ${ }^{17,18,22,23}$

The GOLD Strategy recommends that hospitals should have specialized care such as respiratory departments and respiratory wards, qualified respiratory health care providers, and pulmonary rehabilitation programs in order to provide optimal care for patients with COPD. ${ }^{16}$ In the present study, we have evaluated current care services for COPD provided by government hospitals in the Eastern province in Saudi Arabia. Gaining knowledge regarding the current COPD care provided allows the identification of existing service limitations in Saudi Arabia and in the Middle East and Northern Africa countries. This is necessary before strategies can be developed that are aimed at further optimizing the quality of COPD care in the Middle East and Northern Africa countries such as Saudi Arabia.

\section{Methods}

A cross-sectional study was conducted from April to August 2013 in the Eastern province in Saudi Arabia. Figure 1 shows the main areas in the Eastern province in Saudi Arabia in which 22 government hospitals were included. The government hospitals included had to meet the following criteria: 1) general hospitals sponsored by the $\mathrm{MOH}$ and Ministry of Higher Education and 2) situated in the Eastern province of Saudi Arabia. Hospitals were excluded if they were 1) specialist hospitals (eg, psychiatric, convalescent, and maternity and children's hospitals sponsored by the $\mathrm{MOH}$ ) or 2) referral hospitals sponsored by the MOH.

One health care professional (Director of one of the Departments of Respiratory Medicine, Internal Medicine, Physiotherapy, Psychiatry, Nutrition, or Nursing) at each hospital was asked to complete our self-developed questionnaire evaluating hospital health care (Figure S1) within a week.

The research protocol was approved by the Southern Adelaide Clinical Human Research Ethics Committee, the Institutional Review Board at $\mathrm{MOH}$ in Saudi Arabia, and the Institutional Review Board at King Fahd Hospital University in Saudi Arabia. All included participants signed a written informed consent.

The questionnaire (Figure S1) was written in English, the official language in Saudi hospitals, and was based on an organizational survey created by the COPD Audit Steering Board. ${ }^{24}$ The original questionnaire has been used in Europe and is valid for use worldwide; ${ }^{24}$ it has been modified to make it suitable for hospitals in Saudi Arabia. The adjusted questionnaire includes 34 open-ended and closed questions to evaluate care within hospital services in terms of their size, equipment status, staffing, treatment, and care provided for patients with COPD. The items can be categorized into two parts: 1) general hospital information ( $n=9)$ and 2) the (respiratory) department and COPD care $(n=25) .{ }^{24}$

\section{Statistical analysis}

All data from the questionnaires were entered into the Statistical Package for Social Sciences (SPSS) Version 19 (IBM Corporation, Armonk, NY, USA). The analyses were descriptive. Continuous variables were summarized by 


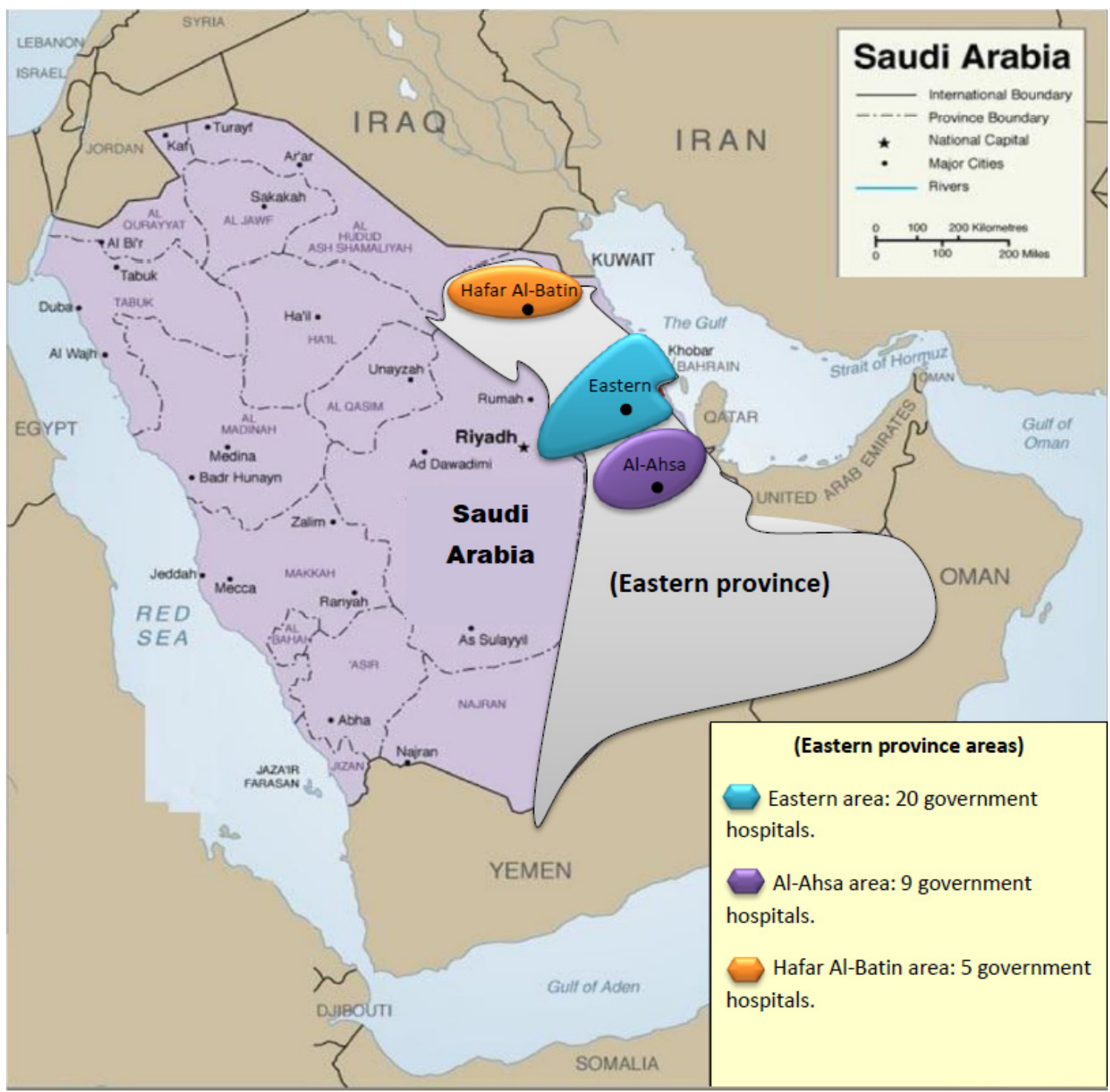

Figure I The main areas in the Eastern province in Saudi Arabia.

Notes: Eastern province is divided in to three main areas: I) Eastern area (Blue area), 2) Al-Ahsa area (Purple area), 3) Hafar Al-Batin area (Orange area).

calculating the mean and standard deviation. Nominal data were given as proportions.

\section{Results}

Of the 34 government hospitals in the Eastern province in Saudi Arabia, 22 met the predefined criteria and were included, whereas 12 were excluded because they were specialist hospitals (psychiatric, Women's and Children's; Figure 2). All 22 included participants were Directors of the Department of Internal Medicine (for characteristics see Table S1), the majority was male $(n=19)$, non-Saudi $(\mathrm{n}=15)$, and Internal Medicine specialists $(\mathrm{n}=12)$. Based on our data, $\sim 4,387,000$ people have access to the included government hospitals (Eastern area $[\mathrm{n}=2,774,000]$, Al-Ahsa area $[\mathrm{n}=1,180,000]$, and Hafar Al-Batin area $[\mathrm{n}=433,000])$.
Table 1 provides a summary of the current care services provided by each hospital in the Eastern province in Saudi Arabia in 2013. The total number of beds available was 3,161. Five hospitals had 300 or more beds, whereas 13 had 50 or fewer beds. None of the hospitals had a respiratory department, but all had an internal medicine department and ward in which patients with COPD could be admitted. Five hospitals (C, G, H, Q, and U) did not admit any patients with COPD in 2012. Only three hospitals (A, K, and $\mathrm{O}$ ) had a specific respiratory outpatient clinic available, whereas in the other 19 hospitals, patients with COPD were referred to the outpatient clinic for internal medicine. Two of these hospitals $(\mathrm{C}$ and $\mathrm{H})$ referred patients with COPD to the nearest hospital (L) due to a lack of facilities to treat patients with COPD. Only five hospitals had spirometry 


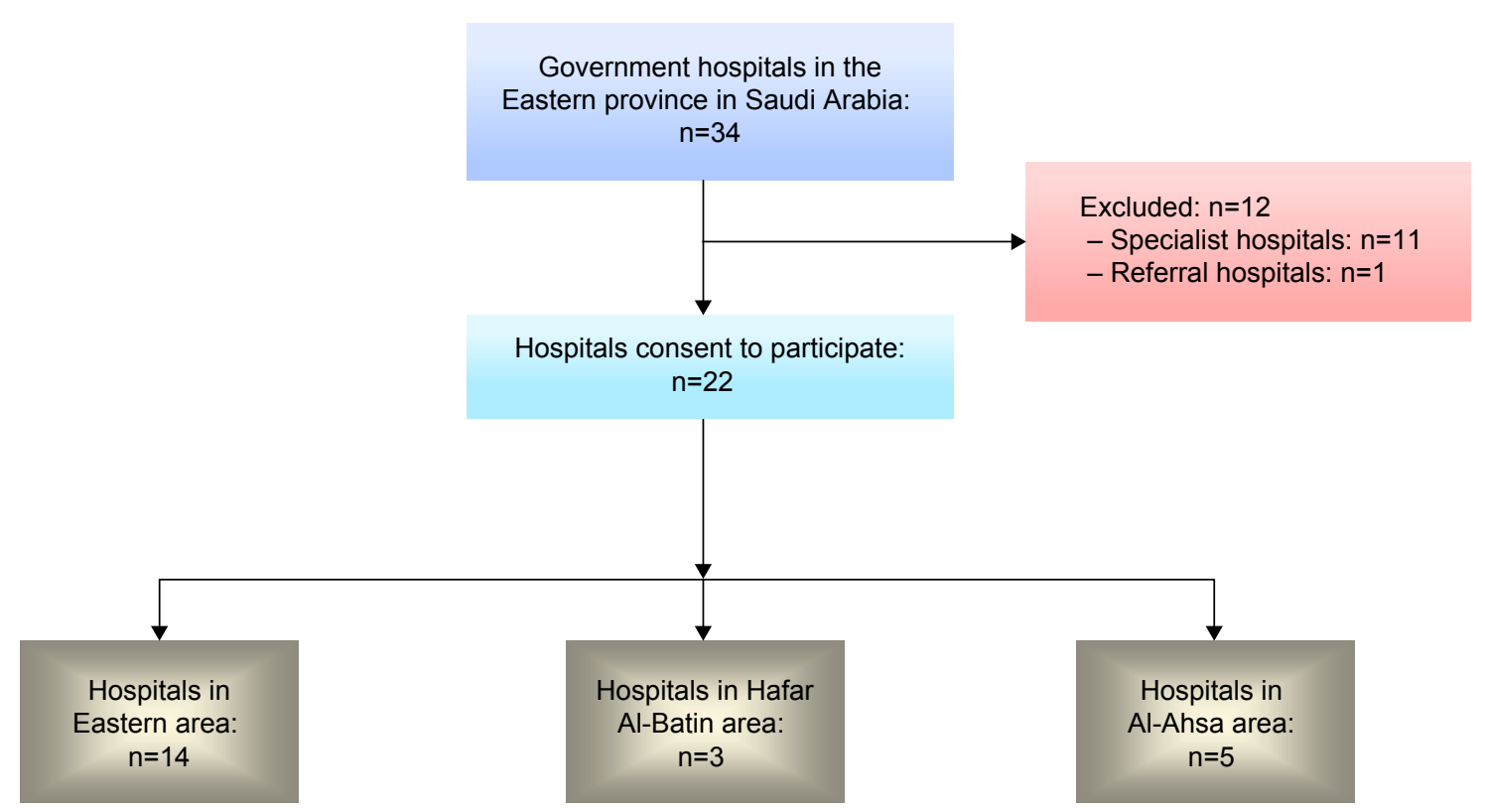

Figure 2 Flow diagram of government hospital's progress through the study.

available, but in one hospital (T), it was not used frequently because of insufficient time to do so. Respiratory physicians $(\mathrm{n}=1)$, technicians $(\mathrm{n}=13)$, and therapists $(\mathrm{n}=11)$ performed spirometry. There were eight hospitals with intensive care units (ICUs), 12 that offered invasive mechanical ventilation for acidotic respiratory failure, and seven that offered noninvasive ventilation. None of the included hospitals offered pulmonary rehabilitation programs or supported discharge programs for patients with COPD (Table 1).

Only five hospitals had qualified respiratory physicians (total: $n=24$ ) and 23 of these physicians worked in the Eastern area $(n=16)$ and Al-Ahsa area $(n=7)$, whereas only one was based in the Hafar Al-Batin area. In 19 hospitals, patients with COPD were seen by internal medicine physicians. Besides physicians, there were 29 respiratory therapists and three physiotherapists involved in COPD care. There were no respiratory nurses, nurse practitioners (only general nurses), mental health specialists, occupational therapists, or dieticians involved in COPD care (Table S2).

Table 2 compares GOLD guideline recommendations with the current care provided in the Eastern province. The hospitals did not meet the GOLD recommendations in terms of having specialized care for patients with COPD such as respiratory departments and respiratory wards, qualified respiratory health care providers, and pulmonary rehabilitation programs. Only five hospitals had some services for COPD management (eg, respiratory physicians, spirometry, and ICUs).

\section{Discussion}

This study is the first to describe the current care services provided by government hospitals to patients with COPD in the Eastern province of Saudi Arabia. Results show that there is a lack of hospital capacity for patients with COPD and that there are limited numbers of specialized health care providers involved in COPD care.

In the Eastern province, the overall number of beds available in government hospitals is relatively low compared to the total population that has access to these hospitals (one bed per 1,387 people). According to the MOH of Saudi Arabia, the average ratio for the whole of Saudi Arabia is one bed for 1,219 people,${ }^{11}$ much lower than in most other countries (Switzerland [one bed for 55 people] and Australia [one bed for 126 people]). ${ }^{25}$ In order to increase the number of beds in Saudi Arabia, the $\mathrm{MOH}$ has recently decided to establish more hospitals in the Eastern province $(\mathrm{n}=6)$, which will add $\sim 1,500$ beds by the end of $2015 .{ }^{26}$

The GOLD guidelines recommend specialized care for respiratory diseases such as COPD in order to ensure optimal care. ${ }^{16}$ Respiratory specialists provide better care for respiratory patients than nonrespiratory medical specialists. ${ }^{27,28}$ Whereas in Europe, most hospitals have respiratory outpatient clinics and patients with COPD are seen by respiratory physicians, ${ }^{24}$ our data show a lack of respiratory inpatient and outpatient clinics and of respiratory physicians. The latter may lead to suboptimal management and provision of care for patients with chronic diseases, especially respiratory diseases. ${ }^{29}$ Although the number of respiratory physicians 


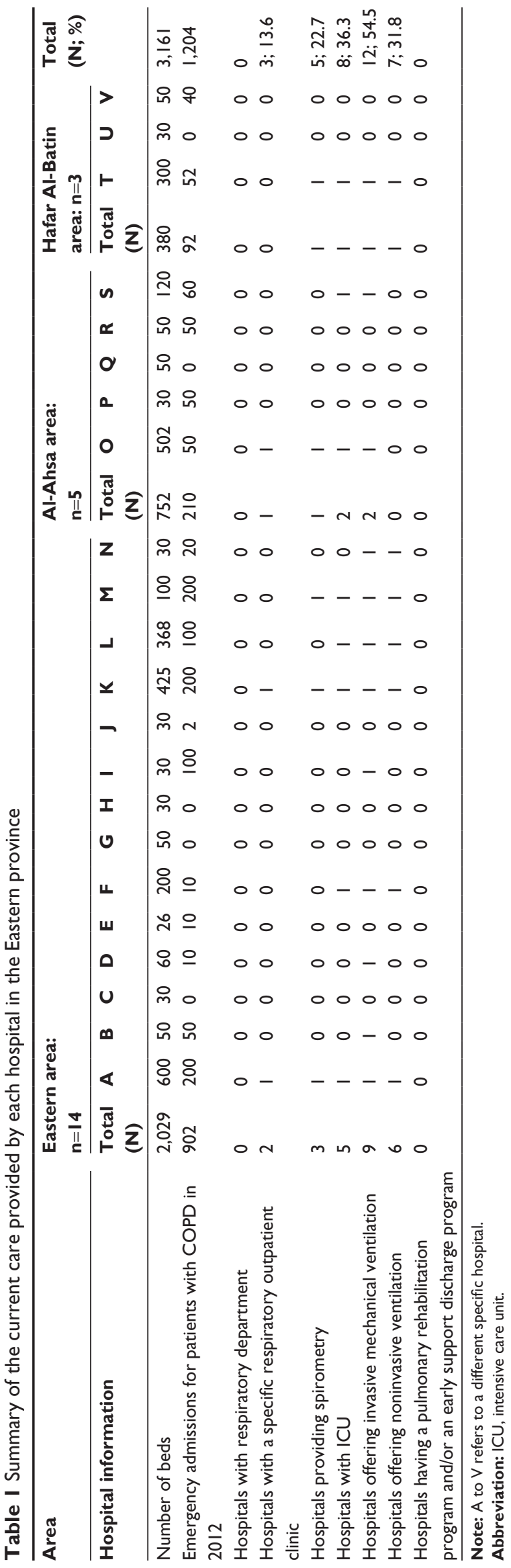

has increased slightly over the last 2 years in the Eastern province, ${ }^{11}$ the total number of Saudi respiratory physicians is still low. ${ }^{11}$ This small number of Saudi physicians is a serious challenge for the $\mathrm{MOH}$. Non-Saudi physicians are likely to have less capacity and ongoing commitment to enhancing the quality of care and systems of management for (respiratory) patients because of their limited stay in Saudi Arabia. ${ }^{15}$ In order to reduce shortages of Saudi physicians, the government could provide more training incentives for local people to study medicine and then to specialize in respiratory medicine. Offering high-quality education in Saudi Arabia and sending students to developed countries for additional education may be useful ways to stimulate this change.

Existing national and international COPD guidelines recommend that spirometry should be used to confirm the diagnosis of COPD. ${ }^{6,7,16,30}$ Our data show that only $22.7 \%$ of hospitals had spirometry available in contrast to almost all hospitals in Europe. ${ }^{24}$ According to the GOLD guidelines, spirometry should not only be used for diagnosis but also to determine the disease severity, to differentiate between asthma and COPD, and to help monitor disease progression. ${ }^{16}$ Studies have shown that misdiagnoses between asthma and COPD frequently exist in Saudi Arabia, which may lead to incorrect treatment and unnecessary deterioration. ${ }^{31,32}$ Increasing awareness of the importance of spirometry use and training in the conduct and interpretation of spirometry have proven to drive uptake of spirometry. ${ }^{33}$

Our data reveal that a lack of ICUs, invasive mechanical ventilation, and noninvasive ventilation for acidotic respiratory failure is another challenge for the $\mathrm{MOH}$ in Saudi Arabia. The presence of ICUs is important in order to provide optimal rescue care for patients with COPD, suffering from acute respiratory failure during exacerbations and requiring ventilation support. ${ }^{16,31}$ A cohort study conducted in Saudi Arabia reported that $33 \%$ of the patients with COPD admitted to ICU were mechanically ventilated. ${ }^{31}$ Patients who are admitted to ICU or to the care of a well-staffed respiratory ward and receive early noninvasive ventilation have an increased chance of surviving. ${ }^{16,31,34-36}$ This has become a standard of care in American and European hospitals ${ }^{24}$ but is not yet available in the Eastern province.

Pulmonary rehabilitation has proven to be effective treatment in patients with COPD. ${ }^{16,37}$ Our data show that pulmonary rehabilitation programs were not available in the included hospitals, and to our best knowledge, only one military hospital is currently offering pulmonary rehabilitation in Saudi Arabia (Central province). ${ }^{7,38}$ The number of patients with COPD who can access pulmonary rehabilitation 
Table 2 Comparison between GOLD guideline recommendations and services available in hospitals in the Eastern province in Saudi Arabia

\begin{tabular}{|c|c|}
\hline GOLD recommendations & Hospitals in the Eastern province $(n=22)$ \\
\hline Specialized care for respiratory diseases & $\begin{array}{l}\text { No respiratory departments and only } 13.6 \% \text { of hospitals } \\
(n=3) \text { have a specific respiratory outpatient clinic }\end{array}$ \\
\hline Spirometry is required to make the diagnosis of COPD & Five hospitals (22.7\%) have spirometry available \\
\hline $\begin{array}{l}\text { COPD assessment must consider the following aspects of the disease separately: } \\
\text { current level of patient's symptoms, severity of the spirometric abnormality, } \\
\text { exacerbation risk, and presence of comorbidities }\end{array}$ & No information available \\
\hline $\begin{array}{l}\text { Pulmonary rehabilitation (PR) program and physical activity is recommended } \\
\text { for all patients with COPD }\end{array}$ & $\begin{array}{l}\text { No PR program and physical activity are offered to patients } \\
\text { with COPD }\end{array}$ \\
\hline $\begin{array}{l}\text { Oxygen therapy is recommended for patients with chronic } \\
\text { respiratory failure }\end{array}$ & $\begin{array}{l}\text { Eight hospitals ( } 36.6 \% \text { ) offer long-term oxygen therapy } \\
\text { for patients with COPD }\end{array}$ \\
\hline $\begin{array}{l}\text { Noninvasive ventilation (NIV) has been shown to improve acute respiratory } \\
\text { acidosis }\end{array}$ & Seven hospitals (31.8\%) offer noninvasive ventilation \\
\hline $\begin{array}{l}\text { Invasive mechanical ventilation is need when patients unable to tolerate } \\
\text { noninvasive mechanical ventilation (severe exacerbations) }\end{array}$ & $\begin{array}{l}\text { Twelve hospitals }(54.5 \%) \text { offer invasive mechanical } \\
\text { ventilation }\end{array}$ \\
\hline Immediate admission to ICU when is needed & Eight hospitals (36.6\%) have an ICU \\
\hline $\begin{array}{l}\text { Smoking cessation is the key intervention for all patients with COPD } \\
\text { who continue to smoke }\end{array}$ & No information available \\
\hline $\begin{array}{l}\text { Pharmacologic therapy such as short-acting anticholinergic, short-acting } \\
\text { bronchodilator, long-acting anticholinergic, long-acting beta2-agonist, } \\
\text { and inhaled corticosteroid is recommended for patients with COPD }\end{array}$ & No information available \\
\hline
\end{tabular}

Abbreviations: GOLD, Global Initiative for Chronic Obstructive Lung Disease; ICU, intensive care unit.

in Saudi Arabia is therefore extremely low, especially compared to countries such as the United Kingdom in which $88 \%$ of hospitals offer pulmonary rehabilitation programs. ${ }^{24}$ Barriers for setting up pulmonary rehabilitation programs in the Eastern province should be investigated, so that implementation of these programs can be facilitated.

Our results show that only limited disciplines were involved in COPD care, whereas there is strong evidence that management of patients with COPD is better if a multidisciplinary team is involved. ${ }^{6,16,37,39}$ This lack of specialized health care providers can be explained by low awareness levels of physicians regarding management of respiratory patients in general and/or lack of knowledge regarding the multidisciplinary approach. Our data also suggest that referrals to other disciplines are extremely scarce. Short courses regarding COPD management, COPD seminars, and inservice education could increase awareness of the benefits of multidisciplinary involvement and increase referral rates. ${ }^{40}$

Results show that most nurses involved in COPD care had general roles, and there was a lack of respiratory nurses. It is rare in Saudi Arabia for the level of education of nurses to extend to bachelor level. ${ }^{41,42}$ Increasing the education of nurses to bachelor level $\mathrm{l}^{41,43}$ and specific training in respiratory diseases is therefore recommended.

The Eastern, Central, and Makkah provinces have higher number of hospitals, beds, health care providers, and funds compared to the other ten provinces in Saudi Arabia. ${ }^{11}$
The fact that the health care services for patients with COPD in the Eastern province, a global hub for chemical industries and most of the oil production, ${ }^{14}$ are far from optimal supports the view that COPD care in government hospitals in the rest of Saudi Arabia and perhaps in nearby countries in the region may also be suboptimal or even worse. ${ }^{21}$

Based on a study performed by the MOH in 2013, it was decided to give extra attention to chronic diseases that have high prevalence rates among Saudis (eg, obesity, hypertension, diabetes, and high cholesterol). ${ }^{44}$ Regrettably, respiratory diseases, the fourth leading cause of death in Saudi Arabia, ${ }^{11,44}$ were not considered a priority. ${ }^{11,44}$ Unfortunately, although most people with respiratory diseases are first seen by general practitioners, studies show that primary care services do not address the respiratory needs of community ambulatory patients, including spirometry. The majority of people with respiratory diseases therefore are seen in government hospitals..$^{45}$ Given that our study results reveal that services and treatments for patients with COPD are suboptimal, there are grounds for expecting the $\mathrm{MOH}$ to provide higher priority for care and management of respiratory diseases, and thereby avoid extra health problems.

In this study, we have not included all hospitals in the Eastern Province, only the hospitals that are under the responsibility of the $\mathrm{MOH}$ and Ministry of Higher Education and that all Saudi citizens have thus free access to. ${ }^{11} \mathrm{~A}$ small 
percentage of the population $(<17 \%)$ visit other specialized government hospitals that are not under the responsibility of the MOH or the Ministry of Higher Education such (eg, military) and $\sim 38 \%$ of the Saudi population visit private hospitals. ${ }^{11}$ We are not aware of the existence of respiratory hospitals in the Eastern province in Saudi Arabia. In our study, we could have chosen to use a structured interview method to obtain more detailed data. However, this would likely have led to the inclusion of fewer directors because of a time constraint. We therefore chose to use established questionnaires. We did not include military, private, or specialized hospitals, which may have more specialized care for patients with COPD, but only targeted government hospitals because every person has access to them. Finally, we have provided results per hospital, and by doing this we have given equal importance to hospitals regardless of their size. This may have influenced the precision of some of the data.

\section{Conclusion and recommendations}

Current services for patients with COPD provided by government hospitals in the Eastern province of Saudi Arabia fall short of GOLD Strategy recommendations because of a lack of hospital capacity, respiratory-specific services, and specialized health care providers involved in COPD care. Increasing the awareness and knowledge regarding optimal COPD management by health care providers may improve the quality of COPD management. Direct support for Saudi people to study medicine and nursing both within their own country and in developed countries would also assist. Finally, models of health financing that enable funding of essential services such as pulmonary rehabilitation and ICUs are urgently needed.

\section{Acknowledgments}

We gratefully acknowledge the Ministry of Higher Education in Saudi Arabia, the Saudi Arabian Cultural Mission in Australia, University of Dammam, and of course all participants who were involved in our study.

\section{Disclosure}

The authors report no conflicts of interest in this work.

\section{References}

1. Tang CY, Taylor NF, Blackstock FC. Chest physiotherapy for patients admitted to hospital with an acute exacerbation of chronic obstructive pulmonary disease (COPD): a systematic review. Physiotherapy. 2010; 96(1):1-13.

2. Effing T, Zielhuis G, Kerstjens H, van der Valk P, van der Palen J. Community based physiotherapeutic exercise in COPD self-management: a randomised controlled trial. Respir Med. 2011;105(3):418-426.
3. Facchiano L, Snyder CH, Núñez DE. A literature review on breathing retraining as a self-management strategy operationalized through Rosswurm and Larrabee's evidence-based practice model. J Am Acad Nurse Pract. 2011;23(8):421-426.

4. Organization WH. Burden of COPD. 2014. [cited March 1, 2014].

5. Polatli M, Ben Kheder A, Wali S, et al. Chronic obstructive pulmonary disease and associated healthcare resource consumption in the Middle East and North Africa: the BREATHE study. Respir Med. 2012;106: S75-S85.

6. Abramson M, Crockett A, Frith P. The COPD-X plan: Australian and New Zealand guidelines for the management of chronic obstructive pulmonary disease. Med J Aust. 2003;178(6):1.

7. Khan JH, Lababidi HM, Al-Moamary MS, et al. The Saudi guidelines for the diagnosis and management of COPD. Ann Thorac Med. 2014; $9(2): 55$.

8. Tageldin MA, Nafti S, Khan JA, et al. Distribution of COPD-related symptoms in the Middle East and North Africa: results of the BREATHE study. Respir Med. 2012;106:S25-S32.

9. Al Ghobain M. The prevalence of chronic obstructive pulmonary disease in Saudi Arabia: where do we stand? Ann Thorac Med. 2011; 6(4):185.

10. Al Ghobain M, Al-Hajjaj MS, Wali SO. Prevalence of chronic obstructive pulmonary disease among smokers attending primary healthcare clinics in Saudi Arabia. Ann Saudi Med. 2011;31(2):129.

11. Health Statistics Year Book. 2014. [cited March 12, 2014].

12. Khattab A, Javaid A, Iraqi G, et al. Smoking habits in the Middle East and North Africa: results of the BREATHE study. Respir Med. 2012; 106:S16-S24.

13. Waness A, El-Sameed YA, Mahboub B. Respiratory disorders in the Middle East: a review. Respirology. 2011;16(5):755-766.

14. Population. 2014. [cited March 1, 2014].

15. Almalki M, Fitzgerald G, Clark M. Health care system in Saudi Arabia: an overview. East Mediterr Health J. 2011;17(10):784-793.

16. Vestbo J, Hurd SS, Agustí AG, et al. Global strategy for the diagnosis, management, and prevention of chronic obstructive pulmonary disease: GOLD executive summary. Am J Respir Crit Care Med. 2013;187(4): 347-365.

17. Desalu OO, Onyedum CC, Adeoti AO, et al. Guideline-based COPD management in a resource-limited setting-physicians' understanding, adherence and barriers: a cross-sectional survey of internal and family medicine hospital-based physicians in Nigeria. Prim Care Respir J. 2013;22(1):79-85.

18. Yawn BP, Wollan PC. Knowledge and attitudes of family physicians coming to COPD continuing medical education. Int J Chron Obstruct Pulmon Dis. 2008;3(2):311.

19. Harvey P, Murphy M, Dornom E, Berlowitz D, Lim W, Jackson B. Implementing evidence-based guidelines: inpatient management of chronic obstructive pulmonary disease. Intern Med J. 2005;35(3): 151-155.

20. Chavez PC, Shokar NK. Diagnosis and management of chronic obstructive pulmonary disease (COPD) in a primary care clinic. COPD. 2009;6(6):446-451.

21. Idrees M, Koniski ML, Taright S, et al. Management of chronic obstructive pulmonary disease in the Middle East and North Africa: results of the BREATHE study. Respir Med. 2012;106:S33-S44.

22. Cabana MD, Rand CS, Powe NR, et al. Why don't physicians follow clinical practice guidelines? JAMA. 1999;282(15):1458-1465.

23. Bourbeau J, Sebaldt RJ, Day A, et al. Practice patterns in the management of chronic obstructive pulmonary disease in primary practice: the CAGE study. Can Respir J. 2008;15(1):13.

24. An International Comparison of COPD Care in Europe, Results of the First European COPD AUDIT European Respiratory Society. 2012. Report No.: ISBN: 978-2-8399-0986-0. Available from: http://www. ersnet.org/images/copd_audit_web_version.pdf. Accessed October 13, 2015.

25. Health Statistics: Hospital Beds. 2014. Available from: http://www. nationmaster.com/ 
26. This Year's Budget will Contribute to Boosting the Health Sector. 2014. [cited Apirl 1, 2014]. Available from: http://www.moh.gov.sa/ en/Ministry/MediaCenter/News/Pages/news-2013-12-23-001.aspx. Accessed October 13, 2015.

27. Angus R, Murray S, Kay J, Thomson N, Patel K. Management of chronic airflow obstruction: differences in practice between respiratory and general physicians. Respir Med. 1994;88(7):493-497.

28. Roberts C, Ryland I, Lowe D, Kelly Y, Bucknall C, Pearson M. Audit of acute admissions of COPD: standards of care and management in the hospital setting. Eur Respir J. 2001;17(3):343-349.

29. Samb B, Desai N, Nishtar S, et al. Prevention and management of chronic disease: a litmus test for health-systems strengthening in low-income and middle-income countries. Lancet. 2010;376(9754):1785-1797.

30. Siafakas N, Vermeire P, Pride NA. Optimal assessment and management of chronic obstructive pulmonary disease (COPD). Eur Respir J. 1995;8(8):1398-1420.

31. Alaithan AM, Memon JI, Rehmani RS, Qureshi AA, Salam A. Chronic obstructive pulmonary disease: hospital and intensive care unit outcomes in the Kingdom of Saudi Arabia. Int J Chron Obstruct Pulmon Dis. 2012;7:819.

32. Al-Kassimi FA, Alhamad EH. Re: prevalence of chronic obstructive pulmonary disease among smokers attending primary health-care clinics in Saudi Arabia. Ann Saudi Med. 2011;31(4):433.

33. Kaminsky DA, Marcy TW, Bachand M, Irvin CG. Knowledge and use of office spirometry for the detection of chronic obstructive pulmonary disease by primary care physicians. Respir Care. 2005;50(12): 1639-1648.

34. Nevins ML, Epstein SK. Predictors of outcome for patients with COPD requiring invasive mechanical ventilation. Chest. 2001;119(6): 1840-1849.

35. Plant P, Owen J, Elliott M. Early use of non-invasive ventilation for acute exacerbations of chronic obstructive pulmonary disease on general respiratory wards: a multicentre randomised controlled trial. Lancet. 2000;355(9219):1931-1935.
36. Chandra D, Stamm JA, Taylor B, et al. Outcomes of noninvasive ventilation for acute exacerbations of chronic obstructive pulmonary disease in the United States, 1998-2008. Am J Respir Crit Care Med. 2012;185(2):152-159.

37. Nici L, Donner C, Wouters E, et al. American thoracic society/European respiratory society statement on pulmonary rehabilitation. Am J Respir Crit Care Med. 2006;173(12):1390-1413.

38. Al Moamary M, Aloriny H, AL-Hajjaj M. Pulmonary rehabilitation: a regional perspective evidenced-based review. Ann Thorac Med. 2014;9(1):3

39. Jenkins S, Hill K, Cecins NM. State of the art: how to set up a pulmonary rehabilitation program. Respirology. 2010;15(8):1157-1173.

40. Johnston KN, Young M, Grimmer KA, Antic R, Frith PA. Barriers to, and facilitators for, referral to pulmonary rehabilitation in COPD patients from the perspective of Australian general practitioners: a qualitative study. Prim Care Respir J. 2013;22(3):319-324.

41. Almalki M, FitzGerald G, Clark M. The nursing profession in Saudi Arabia: an overview. Int Nurs Rev. 2011;58(3):304-311.

42. Al Thagafi H. Change of Attitudes Towards the Nursing Profession for a Sample of Saudi Youth Through a Counselling Program: Experimental Study on a Sample of Students. Naif Arab University for Security Sciences; Riyadh, Saudi Arabia, 2006.

43. Al-Freihi H. A meeting with the secretary-general of the Saudi commission for health specialties. Health Forum. 2009;2009:5-7.

44. Arabia TMoHoS. Survey of Health Information in the Kingdom of Saudi Arabia. 2013. [cited August 9, 2014].

45. Hanan A-A, Roland M. Quality of primary health care in Saudi Arabia: a comprehensive review. Int J Qual Health Care. 2005;17(4):331-346. 


\section{Supplementary materials}

Table SI Characteristics of the Directors of Department of Internal Medicine $(\mathrm{n}=22)$

\begin{tabular}{ll}
\hline Age (mean $\pm \mathrm{SD}$; years) & $45.40 \pm 9.3 \mathrm{I}$ \\
Male (N; \%) & $19(86.4)$ \\
Nationality (N; \%) & $7(31.8)$ \\
$\quad$ Saudi & $15(68.2)$ \\
$\quad$ Non-Saudi & \\
Position (N; \%) & $7(31.8)$ \\
$\quad$ Internal medicine consultant & $12(54.5)$ \\
Internal medicine specialist & $3(13.6)$ \\
Respiratory physician consultant & \\
\hline
\end{tabular}

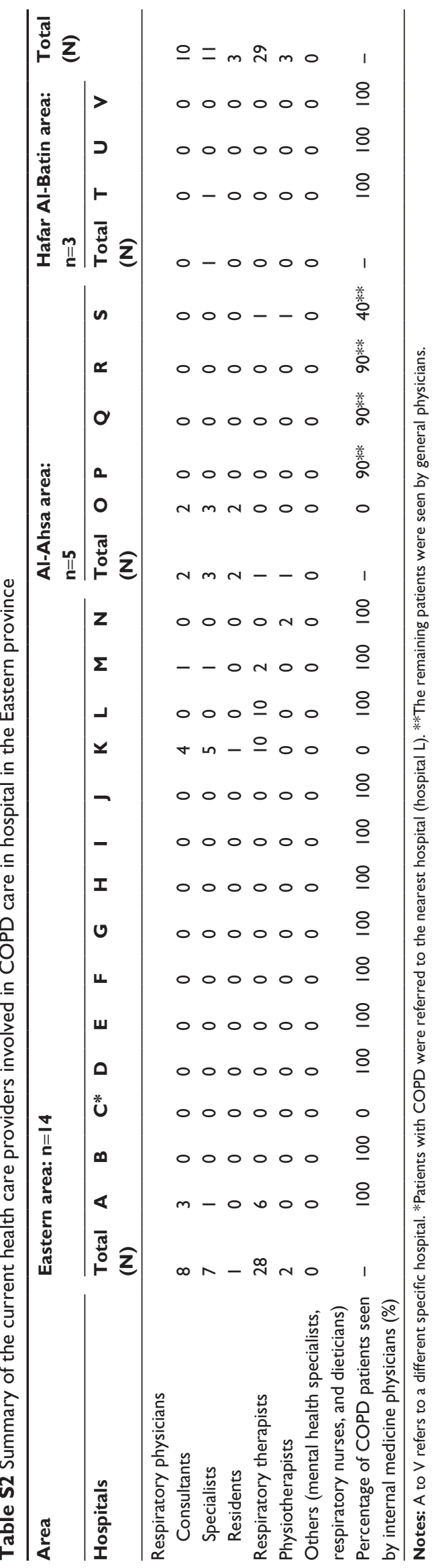




\section{Organizational survey}

Hospital name:

Department:

Name:

Position:

Gender: $\quad$ Male $\square$ Female $\square$

Nationality:

1. What is the total number of beds in your hospital?

2. How many people have access to your hospital?

3. Does your hospital have a respiratory department?
$\square$ Yes
If yes, please go to question 5

4. Does your hospital have an internal medicine department that admits respiratory patients such as chronic obstructive pulmonary disease (COPD) and asthma?

$\square$ Yes
$\square$ No

If no, please tell us which department admits respiratory patients such as (COPD) and asthma:

Please, go to question 9.

5. Does your hospital have a specific respiratory outpatient clinic available?

$\begin{array}{ll}\text { Yes } & \text { If yes, please go to question } 7 \\ \text { No } & \end{array}$

6. Does your hospital have an internal medicine outpatient clinic that admits respiratory patients such as COPD and asthma?

$\square$ Yes

No

7. Does your hospital have a respiratory ward?

$\begin{array}{ll}\square & \text { Yes } \\ \text { No } & \text { If yes, please go to question } 9\end{array}$

8. Does your hospital have an internal medicine ward that admits respiratory patients such as COPD and asthma?

$\square$ Yes

9. Does your hospital have a respiratory team?
$\square$ Yes
No

10. Is there a qualified respiratory physician on call every day of the year?
Yes
No

11. Does your hospital have spirometry available?
1 Yes
No 
12. How many emergency admissions for patients with COPD did your hospital take in 2012?

13. How many qualified respiratory physicians are there in your hospital?
$\square$ Consultants
$\square$ Specialists
$\square$ Residents

14. How many nurses specialising in respiratory diseases are there in your hospital?

\begin{tabular}{l}
$\square$ Respiratory nurses \\
\hline$\square$ Respiratory nurses practitioners
\end{tabular}

15. How many physiotherapists/respiratory therapists are involved in COPD care in your hospital?

\begin{tabular}{|l}
\hline \\
\hline
\end{tabular} Physiotherapists

16. How many pulmonary function technicians are there in your hospital?

17. How many respiratory therapists are involved in pulmonary function testing are there in your hospital?

18. In your hospital what percentage of pulmonary function testing is performed by:

\begin{tabular}{|l|l|}
\hline$\%$ & Technicians \\
\hline$\%$ & Respiratory therapists \\
\hline$\%$ & Others (Please specify them) \\
\hline
\end{tabular}

19. Does your hospital operate a system of specialty triage for COPD?

$\square$ Yes

If yes, please explain:

20. What percentage of COPD outpatients in your hospital are seen by each of the following health care providers?

\begin{tabular}{|c|c|}
\hline$\%$ & Respiratory physicians (ie, consultants, specialists and residents) \\
\hline$\%$ & General physicians \\
\hline$\%$ & Internal medicine physicians \\
\hline$\%$ & Physiotherapist \\
\hline$\%$ & Respiratory therapists \\
\hline$\%$ & Respiratory nurses \\
\hline$\%$ & Respiratory nurses practitioners \\
\hline$\%$ & Mental health specialists (ie, psychiatrist, psychologists and mental health nurses) \\
\hline$\%$ & Dieticians \\
\hline$\%$ & Occupational therapists \\
\hline$\%$ & 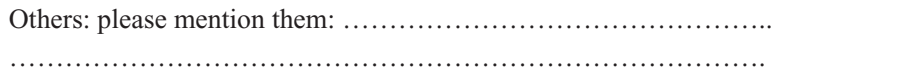 \\
\hline
\end{tabular}

Figure SI (Continued) 
21. What percentage of COPD patients are seen by each of the following health care providers during an admission in your hospital?

\begin{tabular}{|c|c|}
\hline$\%$ & Respiratory physicians (ie, consultants, specialists and residents) \\
\hline$\%$ & General physicians \\
\hline$\%$ & Internal medicine physicians \\
\hline$\%$ & Physiotherapist \\
\hline$\%$ & Respiratory therapists \\
\hline$\%$ & Respiratory nurses \\
\hline$\%$ & Respiratory nurses practitioners \\
\hline$\%$ & Mental health specialists (ie, psychiatrist, psychologists and mental health nurses) \\
\hline$\%$ & Dieticians \\
\hline$\%$ & Occupational therapists \\
\hline$\%$ & Others: please mention them: \\
\hline
\end{tabular}

22. Does your hospital have an Intensive Care Unit (ICU)?

$\square$ Yes

23. Does your hospital offer non-invasive ventilation for acidotic respiratory failure patients?

$\square$ Yes
$\square$ No

24. Does your hospital offer invasive mechanical ventilation for acidotic respiratory failure patients?

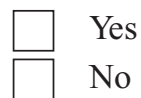

25. Does your hospital have access to a pulmonary rehabilitation program for patients with COPD?

$\square$ Yes

No If no, please go to question 31

26. What type of pulmonary rehabilitation program do you carry out? (Please tick all of the boxes that apply).

Outpatient

Inpatient

Exercise only

Education only

Exercise and education

Others pleases mention them:

27. How many weeks is the program?

28. How many COPD patients are included in each pulmonary rehabilitation program?

29. How many sessions are included in the pulmonary rehabilitation program?

Figure SI (Continued) 
30. What health care providers are involved in the pulmonary rehabilitation program? (Please tick all of the boxes that apply).

\begin{tabular}{|c|}
\hline Respiratory physicians (ie, consultants, specialists and residents) \\
\hline General physicians \\
\hline Internal medicine physicians \\
\hline Physiotherapist \\
\hline Respiratory therapists \\
\hline Respiratory nurses \\
\hline Respiratory nurses practitioners \\
\hline Mental health specialists (ie, psychiatrist, psychologists and mental health nurses) \\
\hline Dieticians \\
\hline Occupational therapists \\
\hline 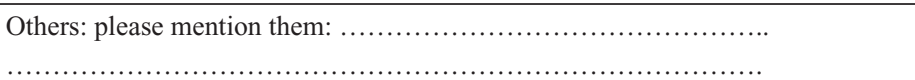 \\
\hline
\end{tabular}

31. Does your hospital operate an early/supported discharge program for COPD admissions?

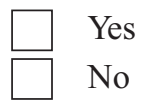

If yes, please explain:

32. To what percentage of COPD admitted to your hospital is this early/supported discharge program offered? $\%$

33. Does your hospital take care of long-term oxygen patients?

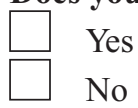

If yes, how many patients per year:

34. Does your hospital take care of home ventilated patients?

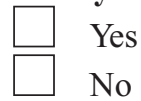

If yes, how many patients per year:

Date:

Signature:

Figure SI Organizational questionnaire used to evaluate care within hospital services for patients with respiratory diseases such as COPD.

Notes: This material has not been reviewed by European Respiratory Society prior to release; therefore the European Respiratory Society may not be responsible for any errors, omissions or inaccuracies, or for any consequences arising there from, in the content. Adapted and reproduced with permission of the European Respiratory Society: An International Comparison of COPD Care in COPD Care in Europe. Results of the First European COPD Audit. Published by European Respiratory Society ( $).$ First Edition 2012.

International Journal of COPD

\section{Publish your work in this journal}

The International Journal of COPD is an international, peer-reviewed journal of therapeutics and pharmacology focusing on concise rapid reporting of clinical studies and reviews in COPD. Special focus is given to the pathophysiological processes underlying the disease, intervention programs, patient focused education, and self management protocols 